\title{
Immune biomarkers in older adults: role of physical activity
}

\author{
Vanessa Valdiglesias ${ }^{\mathrm{a}}$, María Sánchez-Flores ${ }^{\mathrm{a}, \mathrm{b}}$, Ana Maseda ${ }^{\mathrm{c}}$, Laura Lorenzo- \\ López ${ }^{\mathrm{c}}$, Diego Marcos-Pérez ${ }^{\mathrm{a}, \mathrm{b}}$, Ana López-Cortón ${ }^{\mathrm{a}}$, Barbara Strasser ${ }^{\mathrm{d}}$, Dietmar \\ Fuchs $^{\mathrm{d}}$, Blanca Laffon ${ }^{\mathrm{a}}$, José C. Millán-Calenti ${ }^{\mathrm{c}}$, and Eduardo Pásaro ${ }^{\mathrm{a}}$ \\ ${ }^{a}$ Universidade da Coruña, DICOMOSA Group, Department of Psychology, Area of Psychobiology, A Coruña, \\ Spain; \\ ${ }^{b}$ Universidade da Coruña, Department of Cell and Molecular Biology, A Coruña, Spain; \\ ${ }^{c}$ Universidade da Coruña, Gerontology Research Group, Instituto de Investigación Biomédica de A Coruña \\ (INIBIC), Complexo Hospitalario Universitario de A Coruña (CHUAC), SERGAS, A Coruña, Spain; \\ ${ }^{d}$ Biocenter, Innsbruck Medical University, Innsbruck, Austria
}

\begin{abstract}
Aging is associated with a decline in the normal functioning of the immune system. Several studies described the relationship between immunological alterations, including immunosenescence and inflammation, and aging or age-related outcomes, such as sarcopenia, depression, and neurodegenerative disorders. Physical activity is known to improve muscle function and to exert a number of benefits on older adult health, including reduced risk for heart and metabolic system chronic diseases. However, the positive influence of physical activity on the immune system has not been elucidated. In order to shed light on the role of physical activity in immune responses of older individuals, a number of immunological parameters comprising \% lymphocyte subsets $\left(\mathrm{CD}^{+}\right.$, $\mathrm{CD}^{+}, \mathrm{CD}^{+}, \mathrm{CD} 19^{+}$, and $\left.\mathrm{CD} 16^{+} 56^{+}\right)$and serum levels of neopterin and tryptophan metabolism products were evaluated in peripheral blood samples of older adults performing normal $(N=170)$ or reduced $(N=89)$ physical activity. In addition, the potential influence of other clinical and epidemiological factors was also considered. Results showed that subjects with reduced physical activity displayed significantly higher levels of $\mathrm{CD} 4^{+} / \mathrm{CD} 8^{+}$ ratio, kynurenine/tryptophan ratio, and serum neopterin, along with lower \%CD $19^{+}$cells and tryptophan concentrations. Further, some immunological biomarkers were associated with cognitive impairment and functional status. These data contribute to reinforce the postulation that physical activity supports healthy aging, particularly by helping to protect the immunological system from aging-related changes.
\end{abstract}




\section{Introduction}

Life expectancy in the developed world has increased exponentially over the last century, with persons aged 70 years and more representing the fastest growing segment of the Western population (Landi et al., 2010). This noted aging population has led to a greater prevalence of age-related infectious diseases and malignancy, due, in part, to the age-related decline in the normal functioning of the immune system termed "immunosenescence" (Simpson et al., 2012). Immunosenescence is characterized by impaired cellular immune functions concomitant with increased inflammatory activity (Bruunsgaard \& Pedersen, 2000). Subsequently, age-related chronic inflammation was shown to be associated with marked alterations in enzymatic pathways that are involved in the biosynthesis of neurotransmitters, such as serotonin (5-HT), dopamine, epinephrine (EPI), and norepinephrine (NE), which play a significant role in regulation of mood, cognitive processes, and neurodegenerative function (Capuron et al., 2011). Accordingly, immunological alterations were identified in a number of neurodegenerative disorders and age-related syndromes including type II diabetes, dementia, and cardiovascular diseases (Fülöp et al., 2016).

The etiology of immunosenescence appears to be multifactorial. Immunosenescence is well known to contribute to less-effective responses to vaccine and to enhance the incidence of infections and malignancy (Simpson et al., 2012). Immunosenescence is also associated with increased risk of mortality, which emphasizes the importance of maintaining the functional integrity of the immune system during the natural course of aging (Bruunsgaard \& Pedersen, 2000; Simpson et al., 2012). Indeed, several components of the immune system show aging-related pronounced changes affecting both innate and adaptive immune responses (Bruunsgaard \& Pedersen, 2000; Deleidi et al., 2015). The innate response includes physical barriers as well as the participation of cells including macrophages, neutrophils, dendritic cells, and natural killer (NK) cells, and microbicide molecules such as nitric oxide and superoxide anion. The adaptive immune response mainly involves $\mathrm{T}$ and $\mathrm{B}$ lymphocytes and their products, cytokines and antibodies, respectively (Terra et al., 2012). Aging was reported to be associated with alterations in both the number and functions of lymphocyte subsets and NK cells and in the levels of several pro-inflammatory and anti-inflammatory cytokines (Miller, 1996).

Physical activity is defined as any movement produced by skeletal muscles that result in energy expenditure above resting (basal) levels. Physical activity broadly encompasses exercise, sports, and physical activities performed part of daily living, occupation, leisure, and active transportation (Garber et al., 2011). Several studies suggested that moderate physical activity carried out as part of everyday activities may be of substantial benefit to older individuals helping to maintain muscle strength and endurance (de Labra et al., 2015), and playing also an important role in lowering cardiovascular risk, reducing blood pressure, elevating high-density lipoprotein cholesterol levels, increasing glucose tolerance, and, lastly, ensuring adequate cerebral perfusion (Pate et al., 1995). All these positive effects help maintain mobility, prolong independence, and reduce risk of all-cause mortality (Landi et al., 2010). However, less is known on the manner in which physical activity may influence immune function in older adults. Some investigators reported that increasing physical activity may be effective for reducing chronic inflammation in older subjects (Woods et al., 2012) and protect against development of a number of age-associated diseases (Mathur \& Pedersen, 2008; Peterson et al., 2009; Terra et al., 2012) suggesting that regular moderate exercise combined with other methods including dietary manipulation may thus be beneficial for maintenance of immune functions in older individuals (Hirokawa, 1997). However, most long-term studies suggest that moderate exercise training exerts little or no effect on immune function in healthy aging populations (Woods et al., 1999; Shinkai et al., 1995; Campbell et al., 2008; Kapasi et al., 2003), leading to investigators to indicate that physical exercise training programs do not markedly result in major restoration of the senescent immune system.

Inconsistencies in the literature regarding immunological responses to physical activity may be due to a lack of consistent exercise protocols and methods for physical activity evaluation (Allison \& Ditor, 2014). It is also noteworthy that inconsistencies may be related to lack of considering potential confounders, such as nutritional state, depressive symptoms, gender, or consumption habits, which may influence the results. Further, even showing positive results in this regard, the mechanisms by which physical activity may reduce persistent inflammation in older adults remain to be elucidated 
(Simpson et al., 2012). Consequently, questions of whether (1) it is possible to modulate, restore, or reverse immune function in aging, and (2) whether physical exercise may affect the process of immunosenescence, remain unanswered, and require further research. Thus, the present study aimed to shed new light on the role of physical activity on the immune system of older adults by determining a number of immunological parameters and considering also the possible influence played by other clinical and epidemiological factors such as age, gender, consumption habits, dependence, nutritional status, cognitive impairment, and depressive symptoms on immune functions.

\section{Materials and methods}

\section{Subjects and sample collection}

A total of 259 volunteer adults, aged at least 65 or older, were recruited from several associations of retired or older people and nursery homes located in Galicia (NW of Spain). All subjects, or their relatives in case of inability, were informed about the study, asked to sign an informed consent form, and complete a questionnaire regarding demographic, lifestyle, and medical information. The study protocol was approved by the Ethics Committee at the University of A Coruña and conformed to the principles embodied in the Declaration of Helsinki. Qualified staff with extensive experience in the gerontology field participated in this investigation for clinical assessment. Participants were excluded if they were taking medications known to affect the immune system or to have any chronic infection such as human immunodeficiency virus, hepatitis $\mathrm{C}$ virus, or hepatitis $\mathrm{B}$ virus.

Table 1 shows the characteristics of the study population. Since the number of current smokers in both groups was too low or null, these were combined with ex-smokers in the category ever smokers. Similarly, only one category of comorbidity was established, grouping subjects with low comorbidity (Charlson's comorbidity index total score $=2, N=47$ ) and high comorbidity (total score $\geq 3, N=33$ ) (Charlson et al., 1987). Alcohol abuse, according to recommendations by Ministry of Health and Spanish Institute for Alcohol Beverages Investigation, was considered as not exceeding 3 standard drink units (SDU)/d for men and woman (Foster \& Marriott, 2006). In Spain, a SDU is the equivalent of $10 \mathrm{~g}$ of pure ethanol (1 beer, or 1 glass of wine, or half measures of spirits) (Saunders et al., 1993). The exact number of SDU was calculated using this formula: size of drink in milliliters $\times$ percent by volume of alcohol $\times$ density of ethanol at room temperature $(0.789 \mathrm{~g} / \mathrm{ml}) / \mathrm{g}$ of ethanol in a SDU $(10 \mathrm{~g}$ in Spain). The low number of malnourished individuals was grouped together with those at risk of malnutrition in a single category. 
Table 1. Description of the Study Population

\begin{tabular}{|c|c|c|}
\hline & $\begin{array}{l}\text { Normal physical } \\
\text { activity }\end{array}$ & $\begin{array}{l}\text { Reduced physical } \\
\text { activity }\end{array}$ \\
\hline Total individuals $N(\%)$ & $170(65.6)$ & $89(34.4)$ \\
\hline \multicolumn{3}{|l|}{ Gender $N(\%)$} \\
\hline Females & $110(64.7)$ & $64(71.9)$ \\
\hline Males & $60(35.3)$ & $25(28.1)$ \\
\hline Age (years old) ${ }^{a}$ & $75.9 \pm 7.1$ & $86.13 \pm 8.0^{\mathrm{d}}$ \\
\hline $65-69$ & $42(24.7)$ & $3(3.4)$ \\
\hline $70-74$ & $37(21.8)$ & $4(4.5)$ \\
\hline $75-79$ & $34(20.0)$ & $13(14.6)$ \\
\hline $80-84$ & $33(19.4)$ & $13(14.6)$ \\
\hline$\geq 85$ & $24(14.1)$ & $56(62.9)$ \\
\hline \multicolumn{3}{|l|}{ Smoking habits $N(\%)$} \\
\hline Nonsmokers & $126(74.1)$ & $74(88.1)^{\mathrm{c}}$ \\
\hline Ever smokers & $44(25.9)$ & $10(11.9)$ \\
\hline No. cigarettes/d ${ }^{\mathrm{a}}$ & $15.88 \pm 11.9$ & $28.0 \pm 16.8^{\mathrm{d}}$ \\
\hline Years smoking ${ }^{\mathrm{a}}$ & $24.5 \pm 15.37$ & $35.4 \pm 19.3$ \\
\hline \multicolumn{3}{|l|}{ Comorbidity $^{\mathrm{b}} N(\%)$} \\
\hline No comorbidity & $128(75.7)$ & $50(56.2)^{\mathrm{c}}$ \\
\hline Comorbidity & $41(24.3)$ & $39(43.8)$ \\
\hline \multicolumn{3}{|l|}{ Taking medication } \\
\hline Number of drugs ${ }^{\mathrm{a}}$ & $4.9 \pm 3.5$ & $9.0 \pm 3.7^{\mathrm{c}}$ \\
\hline No polimedication ( $<5$ drugs) & $85(50.0)$ & $11(12.4)^{\mathrm{c}}$ \\
\hline Polimedication ( $\geq 5$ drugs) & $85(50.0)$ & $78(87.6)$ \\
\hline \multicolumn{3}{|l|}{ Alcohol consumption $N(\%)$} \\
\hline No & $92(54.1)$ & $81(91.0)^{\mathrm{c}}$ \\
\hline Yes & $78(45.9)$ & $8(9.0)$ \\
\hline \multicolumn{3}{|l|}{ Alcohol abuse $N(\%)$} \\
\hline No & $161(94.7)$ & $89(100.0)^{\mathrm{c}}$ \\
\hline Yes & $9(5.3)$ & $0(0.0)$ \\
\hline \multicolumn{3}{|l|}{ Caffeine beverages consumption $N(\%)$} \\
\hline No & $64(37.6)$ & $78(87.6)^{\mathrm{c}}$ \\
\hline Yes & $106(62.4)$ & $11(12.4)$ \\
\hline \multicolumn{3}{|l|}{ Living conditions $N(\%)$} \\
\hline Family home & $155(91.2)$ & $3(3.4)^{\mathrm{c}}$ \\
\hline Family home + daycare center & $4(2.3)$ & $23(25.8)$ \\
\hline Nursing home & $11(6.5)$ & $63(70.8)$ \\
\hline
\end{tabular}

${ }^{a}$ Mean \pm standard deviation; ${ }^{b}$ according to Charlson's comorbidity index; 'significantly different (Chi-square test, bilateral); ${ }^{\mathrm{d}}$ significantly different (Student's $t$-test, bilateral).

Whole blood was collected into vacutainer tubes containing EDTA as anticoagulant for the analysis of lymphocyte subsets, and without anticoagulant for determination of all other biomarkers in serum. All samples were coded at the moment of collection to ensure a blind study. Samples were all taken in the morning to avoid circadian changes in levels of immune parameters and transported to the lab immediately, where they were processed within $4 \mathrm{~h}$ of collection. 


\section{Physical activity}

Physical activity performed by study subjects was measured using Minnesota Leisure Time Activity questionnaire, following the Spanish version validated by Ruiz Comellas et al. (2012). Six activities are addressed in this questionnaire, including walking, gardening, sport/dancing, climbing stairs, shopping walking, and cleaning house. Physical activity was calculated as a weighted score of kilocalories (Kcal) expended per week on the basis of the information obtained from each participant and adjusted by gender. The threshold to determine low physical activity was established at $<383$ $\mathrm{Kcal} /$ week for males and $<270 \mathrm{Kcal} /$ week for females (Fried et al., 2001). Due to the cognitive impairment of some nursing home residents, the presence of normal/reduced physical activity was documented by the physiotherapist of the patient.

\section{Comorbidity}

For all patients, general comorbidity and number of comorbid diseases were registered using the Charlson comorbidity index (CCI; Charlson et al., 1987). For each patient, a CCI aged-adjusted score was computed, coding comorbid diseases as $0=$ absent and $1-6=$ present.

\section{Prescription medication use}

The participants were asked to present their drug history as prescribed medications by their general practitioner. Each medication name and current clinical diagnosis were noted. Polypharmacy has been defined as the concomitant use of five or more different prescription medications (Gnjidic et al., 2012).

\section{Nutritional status}

The Mini-Nutritional Assessment-Short Form (MNA-SF, Kaiser et al., 2009) used for nutritional screening is composed of six questions extracted from the full MNA questionnaire (Guigoz et al., 1994): declined food intake over the past 3 months due to appetite loss, digestive problems, chewing, or swallowing difficulties; involuntary weight loss during the last 3 months; mobility; psychological stress or acute disease in the past 3 months; neuropsychological problems (severe dementia or depression); and body mass index. The sum of the MNA-SF score distinguishes between subjects with: (1) normal nutritional status, MNA-SF between 12 and 14 points; (2) at risk of malnutrition, MNA-SF 8-11 points; and (3) malnourished, MNA-SF 0-7 points. The Spanish version of the MNASF was used in this study (Nestlé Nutrition Institute, 2009).

\section{Cognitive and affective assessment}

The global cognitive status was assessed using the Spanish version of the Mini-Mental State Examination (MMSE; Folstein et al., 1975) scale, which examines several areas of cognitive function: orientation to time and place, short-term memory, attention, visual-spatial skills, language, and praxis. MMSE scores, ranging from 0 to 30, were adjusted for age and level of education, and participants were considered as cognitively impaired if they scored $\leq 24$ (Blesa et al., 2001). Depressive symptoms were assessed using the short-form of the Geriatric Depression Scale (Sheikh \& Yesavage, 1986), a 15-item scale specifically developed for screening depressive symptoms in older populations. A Spanish-validated version of the test adapted for patients $>65$ years (Martínez de la Iglesia et al., 2002), which recommends using a cutoff of 5 or more points to consider the existence of probable clinical depression was administered. 
The patients' functional status, defined as the capacity to perform basic everyday tasks, was assessed by an occupational therapist using the Barthel index (Mahoney \& Barthel, 1965) validated for Spanish population (Baztán et al., 1993). This index measures the following 10 activities of daily living (ADL): feeding, bathing, dressing, grooming, bowels, bladder, toilet use, transfers, mobility, and stairs. The item scores are summed to create a total score. The subjects were classified as independent in ADL (score of 100, or 90 in case the patient uses a wheelchair) or dependent in ADL (patients scoring: $<20$, total dependence; $20-35$, severe dependence; $40-55$, moderate dependence; and $\geq 60$, mild dependence) (Baztán et al., 1993).

\section{Lymphocyte subpopulations}

The \% different lymphocyte subpopulations (T lymphocytes $\left[\mathrm{CD}^{+}\right]$, T-helper lymphocytes $\left[\mathrm{CD} 4^{+}\right], \mathrm{T}$-cytotoxic lymphocytes $\left[\mathrm{CD} 8^{+}\right]$, B-lymphocytes $\left[\mathrm{CD} 19^{+}\right]$, and NK cells $\left[\mathrm{CD} 16^{+} 56^{+}\right]$) were determined in fresh whole blood samples $(100 \mu \mathrm{l})$ by three-color direct immunofluorescence surface marker analysis, using flow cytometry according to previously described protocols (García-Lestón et al., 2011). A FACScalibur flow cytometer and Cell Quest Pro software (Becton Dickinson) were used for the analyses. At least $10^{4}$ events in the lymphocytes window were acquired.

\section{Neopterin}

Serum neopterin concentration was determined by means of a commercially available ELISA kit (BRAHMS, Hennigsdorf, Germany), following manufacturer's instructions.

\section{Tryptophan and kynurenine}

A high-performance liquid chromatography (HPLC) methodology was used to measure tryptophan and kynurenine concentrations in serum samples, employing 3-nitro-l-tyrosine as internal standard, according to Widner et al. (1997). The extent of tryptophan breakdown was estimated by calculating the kynurenine to tryptophan ratio ( $\mathrm{Kyn} / \mathrm{Trp})$, expressed in micromoles kynurenine per millimole tryptophan.

\section{Statistical analysis}

Population description, comparing groups with normal and reduced physical activity by sociodemographic factors, lifestyle factors, and clinical parameters was carried out by univariate analysis. Continuous variables were compared with Student's $t$-test and categorical variables were compared by Pearson's Chi-square test.

The effect of physical activity was preliminarily evaluated by Student's $t$-test. Data from the variables $\% \mathrm{CD}^{+}, \% \mathrm{CD} 4^{+}, \% \mathrm{CD} 16^{+} 56^{+}$, tryptophan, and kynurenine followed a normal distribution (Kolmogorov-Smirnov goodness-of-fit test). A logarithmic transformation of data was applied to $\% \mathrm{CD}^{+}, \% \mathrm{CD} 19^{+}$, and $\mathrm{Kyn} / \mathrm{Trp}$ to achieve a better approximation to the normal distribution. As no improvement was achieved with transformation, the Mann-Whitney $U$ test was applied to $\mathrm{CD} 4^{+} / \mathrm{CD} 8^{+}$rate and neopterin data.

A multiple linear regression analysis was performed to estimate the effect of physical activity and possible confounders on the log-transformed data. All models included age, gender and smoking habits, and parameter-specific actual confounders. Confounders were obtained by stepwise analyses and resulted to be cognitive impairment for $\% \mathrm{CD}^{+}, \% \mathrm{CD} 8^{+}$, and $\% \mathrm{CD} 16^{+} 56^{+}$lymphocytes, and dependence for $\% \mathrm{CD} 8^{+}$and $\% \mathrm{CD} 19^{+}$cells, and for $\mathrm{Kyn} / \mathrm{Trp}$ ratio. The results are presented as mean ratios (MR) and $95 \%$ confidence intervals $(95 \% \mathrm{CI})$. Spearman's rank correlation was applied to 
search for associations between variables. All analyses were performed using the STATA/SE software package V. 12.0 (StataCorp LP) and the IBM SPSS software package V. 20 (SPSS, Inc.). Statistical significance level was set at .05.

\section{Results}

\section{Descriptive characteristics}

The total population included in this study comprised 259 older adults. Among them, $65.6 \%$ of the individuals were noted to perform normal physical activity whereas physical activity carried out by the remaining $34.4 \%$ was reduced. This last group was (1) significantly older with $62.9 \%$ of individuals aged 85 or older, (2) included less ever smokers (no current smokers and just 10 exsmokers), and (3) showed a higher degree of comorbidity according to Charlson's index. No marked differences were found in gender distribution, but some daily habits resulted in differences between groups with normal and reduced physical activity. Thus, alcohol and caffeine consumption was significantly lower in individuals with reduced physical activity, with no subjects displaying alcohol abuse and just $12.4 \%$ consuming caffeine beverages. All subjects with alcohol abuse behavior performed normal physical activity and resided in a family home. The number of drugs prescribed to subjects with normal physical activity was lower, with half of them taking less than 5 drugs/d, whereas nearly $90 \%$ of individuals with low physical activity took 5 or more drugs/d. Regarding living conditions, a majority (93.6\%) of individuals with normal physical activity resided in a family home, with only $2.4 \%$ attending daycare centers, whereas $70.8 \%$ of the population with reduced physical activity lived in a nursing home, and $25.8 \%$ attended a daycare center.

The description of the clinical parameters of both study groups is presented in Table 2. Significant differences were found between normal and reduced physical activity groups in all clinical parameters considered including nutritional status as evidenced by categories or score obtained by MNA-SF, cognitive impairment, depressive symptoms, and ADL dependence; individuals with reduced physical activity demonstrated worse clinical conditions in all cases.

Table 2. Description of Clinical Parameters in the Study Groups.

\begin{tabular}{lcc}
\hline & $\begin{array}{c}\text { Normal physical } \\
\text { activity }\end{array}$ & $\begin{array}{c}\text { Reduced physical } \\
\text { activity }\end{array}$ \\
\hline Nutrition $N(\%)$ & & \\
$\quad$ Normal nutrition & $140(82.8)$ & $20(23.5)^{\mathrm{b}}$ \\
At risk or malnourished & $29(17.2)$ & $65(76.5)$ \\
MNA-SF score & $12.9 \pm 1.6$ & $9.7 \pm 2.5^{\mathrm{c}}$ \\
Cognitive impairment $N(\%)$ & & \\
No & $161(94.7)$ & $15(18.3)^{\mathrm{b}}$ \\
Yes & $9(5.3)$ & $67(81.7)$ \\
Depressive symptoms $N(\%)$ & & $49(55.1)^{\mathrm{b}}$ \\
No & $157(92.4)$ & $40(44.9)$ \\
Yes & $13(7.6)$ & $2(2.3)^{\mathrm{b}}$ \\
Dependence $N(\%)$ & $150(88.2)$ & $86(97.7)$ \\
No & $20(11.8)$ & \\
Yes & & \\
\hline
\end{tabular}

${ }^{a}$ Mean \pm standard deviation; ${ }^{b}$ significantly different (Chi-square test, bilateral); ${ }^{c}$ significantly different (Student's t-test, bilateral). 
Results of the different immunological biomarkers analyzed in the present study and their corresponding published reference range in older individuals are presented in Table 3 . According to univariant analyses, significant higher serum neopterin levels and Kyn/Trp ratio, a numerical rise in $\mathrm{CD} 4^{+} / \mathrm{CD} 8^{+}$ratio, together with significantly lower $\% \mathrm{CD} 19^{+}$cells and tryptophan concentrations, was found in subjects with reduced physical activity compared with those performing normal activity. In addition, the \% individuals with immunological parameters out of reference ranges were generally higher in the former group with the exception of $\% \mathrm{CD} 3^{+}$lymphocytes and tryptophan levels. Interesting and significant associations were observed for $\% \mathrm{CD}_{1} 9^{+}$cells with neopterin $(r=-.309)$, and with Kyn/Trp ratio $(r=-.313)$; and also for neopterin levels with tryptophan $(r=-.429)$ and kynurenine $(r=.397)$ concentrations, and with Kyn/Trp ratio $(r=.72)$

Table 3. Results of Biomarkers in the Study Groups (Univariate Analysis) and Percentage Falling within the Corresponding Reference Ranges.

\begin{tabular}{|c|c|c|c|c|c|c|c|}
\hline & \multirow[b]{2}{*}{ Reference range $^{a}$} & \multicolumn{3}{|c|}{ Normal physical activity } & \multicolumn{3}{|c|}{ Reduced physical activity } \\
\hline & & $N$ & Mean \pm SD & $\begin{array}{c}\% \text { Within } \\
\text { reference range }\end{array}$ & $N$ & Mean \pm SD & $\begin{array}{l}\% \text { Within } \\
\text { reference range }\end{array}$ \\
\hline$\% \mathrm{CD}^{+}$ & $51.24-92.16^{\mathrm{b}}$ & 162 & $71.66 \pm 11.00$ & 94.4 & 87 & $73.78 \pm 10.60$ & 96.6 \\
\hline$\% \mathrm{CD}^{+}$ & $19.80-64.32^{\mathrm{b}}$ & 162 & $43.20 \pm 11.65$ & 95.1 & 68 & $43.98 \pm 11.82$ & 91.2 \\
\hline$\% \mathrm{CD}^{+}$ & $8.28-54.17^{\mathrm{b}}$ & 162 & $23.33 \pm 11.21$ & 93.8 & 87 & $22.16 \pm 12.43$ & 88.5 \\
\hline $\mathrm{CD}^{+} / \mathrm{CD}^{+}$ & $0.46-6.57^{b}$ & 162 & $2.64 \pm 3.21$ & 93.8 & 68 & $3.21 \pm 2.98$ & $83.8^{\mathrm{f}}$ \\
\hline$\% \mathrm{CD} 19^{+}$ & $1.94-20.15^{\mathrm{b}}$ & 162 & $7.32 \pm 4.51$ & 95.7 & 68 & $5.74 \pm 3.40^{\mathrm{e}}$ & $88.2^{\mathrm{f}}$ \\
\hline$\% \mathrm{CD} 16^{+} 56^{+}$ & $0.61-36.93^{b}$ & 162 & $18.90 \pm 9.18$ & 96.9 & 87 & $18.25 \pm 9.54$ & 94.3 \\
\hline Neopterin (nmol/l) & $0.0-19.7^{\mathrm{c}}$ & 157 & $6.95 \pm 4.10$ & 97.5 & 86 & $13.42 \pm 7.88^{\mathrm{e}}$ & $81.4^{\mathrm{f}}$ \\
\hline Tryptophan $(\mu \mathrm{mol} / 1)$ & $44.2-81.4^{\mathrm{d}}$ & 154 & $77.44 \pm 15.53$ & 68.8 & 85 & $62.15 \pm 14.77^{\mathrm{e}}$ & $77.6^{\mathrm{f}}$ \\
\hline Kynurenine $(\mu \mathrm{mol} / \mathrm{l})$ & $1.1-3.9^{\mathrm{d}}$ & 154 & $2.38 \pm .72$ & 96.7 & 85 & $2.46 \pm .82$ & 96.3 \\
\hline $\mathrm{Kyn} / \operatorname{Trp}(\mu \mathrm{mol} / \mathrm{mmol})$ & $14.3-67.1^{\mathrm{d}}$ & 154 & $40.72 \pm 21.14$ & 87.7 & 85 & $83.97 \pm 36.03^{\mathrm{e}}$ & $30.6^{\mathrm{f}}$ \\
\hline
\end{tabular}

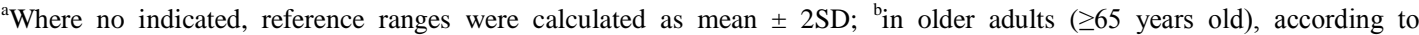

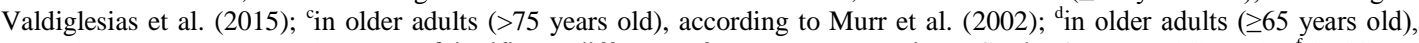
according to Capuron et al. (2011); ${ }^{\mathrm{e}}$ significant difference for means comparison: Student's $t$-test (bilateral); ${ }^{\mathrm{f}}$ significant difference for percentages comparison: Chi-square test (bilateral).

Results from multivariate statistical analysis are presented in Tables 4-6. All models were significant and corrected for gender, age, and smoking habits; actual confounders were investigated including alcohol and caffeine consumption as well as all clinical parameters. Tables 4 and 5 illustrate the effect of physical activity, gender, age, and smoking habits on lymphocyte subsets (Table 4), and on neopterin and tryptophan metabolism products (Table 5). In agreement with previous univariate analysis, reduced physical activity group was found to show significantly higher levels of $\mathrm{CD} 4^{+} / \mathrm{CD}^{+}$ratio and neopterin concentrations, but significantly lower levels of tryptophan. However, no marked differences were found between groups either in \%CD19 ${ }^{+}$cells or in Kyn/Trp ratio. Further, generally reduced values of all lymphocytes subsets were observed in males compared to females (significant for $\% \mathrm{CD} 19^{+}$and $\% \mathrm{CD} 3^{+}$cells), but not for $\% \mathrm{CD} 16^{+} 56^{+}$cells, which displayed significantly higher levels in males. A decreasing influence of age was noted in $\% \mathrm{CD}^{+}, \mathrm{CD}^{+}$and $\mathrm{CD} 19^{+}$cells, $\mathrm{CD} 4^{+} / \mathrm{CD}^{+}$ratio, and tryptophan serum concentrations, while levels of neopterin, kynurenine, and $\mathrm{Kyn} / \mathrm{Trp}$ ratio were observed with increasing age. In contrast, no marked influence of smoking habits was detected in any case. 
Table 4. Effect of Physical Activity, Gender, Age and Smoking Habits on Lymphocytes Subsets. Log Linear Regression Estimates Adjusted for Parameter-Specific Actual Confounders.

\begin{tabular}{|c|c|c|c|c|c|c|c|c|c|c|c|c|}
\hline & \multicolumn{2}{|c|}{$\% \mathrm{CD}^{+}$} & \multicolumn{2}{|c|}{$\% \mathrm{CD}^{+}$} & \multicolumn{2}{|c|}{$\% \mathrm{CD}^{+}$} & \multicolumn{2}{|c|}{$\mathrm{CD} 4^{+} / \mathrm{CD}^{+}{ }^{+}$} & \multicolumn{2}{|c|}{$\% \mathrm{CD} 19^{+}$} & \multicolumn{2}{|c|}{$\% \mathrm{CD} 16^{+} 56^{+}$} \\
\hline & Mean ratio & $95 \% \mathrm{CI}$ & Mean ratio & $95 \% \mathrm{CI}$ & Mean ratio & $95 \% \mathrm{CI}$ & Mean ratio & $95 \% \mathrm{CI}$ & Mean ratio & $95 \% \mathrm{CI}$ & Mean ratio & $95 \% \mathrm{CI}$ \\
\hline \multicolumn{13}{|l|}{ Physical activity } \\
\hline Normal & 1.00 & & 1.00 & & 1.00 & & 1.00 & & 1.00 & & 1.00 & \\
\hline Reduced & .98 & $(.90-1.06)$ & 1.22 & $(.99-1.50)$ & 1.15 & $(.75-1.77)$ & $1.45^{*}$ & $(1.08-1.96)$ & 1.27 & $(.79-2.04)$ & 1.18 & $(.89-1.56)$ \\
\hline \multicolumn{13}{|l|}{ Gender } \\
\hline Females & 1.00 & & 1.00 & & 1.00 & & 1.00 & & 1.00 & & 1.00 & \\
\hline Males & $.95^{*}$ & $(.90-.99)$ & .86 & $(.71-1.05)$ & .98 & $(.82-1.15)$ & .85 & $(.64-1.13)$ & $.74 *$ & $(.61-.90)$ & $1.26^{*}$ & $(1.05-1.51)$ \\
\hline Age (years) & $.99 *$ & $(.99-.99)$ & $.98^{*}$ & $(.97-.99)$ & 1.00 & $(.99-1.01)$ & $.97 *$ & $(.96-.99)$ & $.99 *$ & $(.98-.99)$ & 1.01 & $(.99-1.02)$ \\
\hline \multicolumn{13}{|l|}{ Smoking habits } \\
\hline Nonsmokers & 1.00 & & 1.00 & & 1.00 & & 1.00 & & 1.00 & & 1.00 & \\
\hline Smokers & 1.04 & $(.98-1.11)$ & 1.10 & $(.88-1.38)$ & 1.13 & $(.92-1.38)$ & 1.03 & $(.74-1.42)$ & 1.04 & $(.83-1.31)$ & .90 & $(.73-1.12)$ \\
\hline
\end{tabular}

CI: Confidence interval; $* P<.05$. 
Table 5. Effect of Physical Activity, Gender, Age, and Smoking Habits on Neopterin and Tryptophan Metabolism Products. Log Linear Regression Estimates Adjusted for Parameter-Specific Actual Confounders.

\begin{tabular}{|c|c|c|c|c|c|c|c|c|}
\hline & \multicolumn{2}{|c|}{ Neopterin } & \multicolumn{2}{|c|}{ Tryptophan } & \multicolumn{2}{|c|}{ Kynurenine } & \multicolumn{2}{|c|}{ Kyn/Trp } \\
\hline & Mean ratio & $95 \% \mathrm{CI}$ & Mean ratio & $95 \% \mathrm{CI}$ & Mean ratio & $95 \% \mathrm{CI}$ & Mean ratio & $95 \% \mathrm{CI}$ \\
\hline \multicolumn{9}{|l|}{ Physical activity } \\
\hline Normal & 1.00 & & 1.00 & & 1.00 & & 1.00 & \\
\hline Reduced & $1.47 *$ & $(1.27-1.70)$ & $.85^{*}$ & $(.80-.91)$ & .94 & $(.85-1.04)$ & .92 & $(.68-1.26)$ \\
\hline \multicolumn{9}{|l|}{ Gender } \\
\hline Females & 1.00 & & 1.00 & & 1.00 & & 1.00 & \\
\hline Males & 1.00 & $(.87-1.16)$ & .98 & $(.92-1.05)$ & 1.01 & $(.92-1.11)$ & 1.10 & $(.97-1.25)$ \\
\hline Age (years) & $1.02 *$ & $(1.01-1.03)$ & $.99 *$ & $(.99-.99)$ & $1.01 *$ & $(1.00-1.02)$ & $1.02 *$ & $(1.01-1.02)$ \\
\hline \multicolumn{9}{|l|}{ Smoking habits } \\
\hline Nonsmokers & 1.00 & & 1.00 & & 1.00 & & 1.00 & \\
\hline Smokers & 1.00 & $(.55-1.83)$ & 1.06 & $(.98-1.15)$ & 1.03 & $(.69-1.57)$ & .91 & $(.78-1.06)$ \\
\hline
\end{tabular}

CI: Confidence interval; $* P<.05$.

Table 6. Effect of Cognitive Impairment and Dependence on Selected Biomarkers. Log Linear Regression Estimates Adjusted for Physical Activity, Gender, Age, Smoking Habits, and Parameter-Specific Actual Confounders.

\begin{tabular}{|c|c|c|c|c|c|c|c|c|c|c|}
\hline & \multicolumn{2}{|c|}{$\% \mathrm{CD}^{+}$} & \multicolumn{2}{|c|}{$\% \mathrm{CD}^{+}$} & \multicolumn{2}{|c|}{$\% \mathrm{CD} 19^{+}$} & \multicolumn{2}{|c|}{$\% \mathrm{CD} 16^{+} 56^{+}$} & \multicolumn{2}{|c|}{ Kyn/Trp } \\
\hline & $\begin{array}{l}\text { Mean } \\
\text { ratio }\end{array}$ & $95 \% \mathrm{CI}$ & $\begin{array}{l}\text { Mean } \\
\text { ratio }\end{array}$ & $95 \% \mathrm{CI}$ & $\begin{array}{l}\text { Mean } \\
\text { ratio }\end{array}$ & $95 \% \mathrm{CI}$ & $\begin{array}{c}\text { Mean } \\
\text { ratio }\end{array}$ & $95 \% \mathrm{CI}$ & $\begin{array}{l}\text { Mean } \\
\text { ratio }\end{array}$ & $\begin{array}{c}95 \% \\
\text { CI }\end{array}$ \\
\hline \multicolumn{11}{|c|}{$\begin{array}{l}\text { Cognitive } \\
\text { impairment }\end{array}$} \\
\hline No & 1.00 & & 1.00 & & & & 1.00 & & & \\
\hline Yes & $1.15^{*}$ & $\begin{array}{c}(1.06- \\
1.24)\end{array}$ & $1.43^{*}$ & $\begin{array}{c}(1.09- \\
1.87)\end{array}$ & & & $.68^{*}$ & $\begin{array}{l}(.52- \\
.89)\end{array}$ & & \\
\hline \multicolumn{11}{|c|}{ Dependence } \\
\hline No & & & 1.00 & & 1.00 & & & & 1.00 & \\
\hline Yes & & & $.57 *$ & $(.37-.87)$ & $.63 *$ & $\begin{array}{l}(.40- \\
1.00)\end{array}$ & & & & \\
\hline
\end{tabular}

CI: Confidence interval; ${ }^{*} P<.05$.

\section{Association between clinical parameters and immunological biomarkers}

Nutritional status and depressive symptoms did not markedly influence any of the immunological biomarkers examined. Since cognitive impairment was identified as a confounder for $\% \mathrm{CD}^{+}$, $\% \mathrm{CD}^{+}$, and \%CD16 ${ }^{+} 56^{+}$lymphocytes, whereas $\mathrm{ADL}$ dependence was a confounder for $\% \mathrm{CD}^{+}$and $\% \mathrm{CD} 19^{+}$cells, and $\mathrm{Kyn} / \mathrm{Trp}$ ratio, results obtained for these clinical parameters were utilized in the multiple linear regression analyses (Table 6). Subjects with cognitive impairment presented higher values of $\% \mathrm{CD}^{+}$and $\% \mathrm{CD}^{+}$cells and a lower $\% \mathrm{CD}^{+} 6^{+} 56^{+}$lymphocytes than those with normal cognitive status. Individuals with ADL dependence demonstrated diminished \% $\mathrm{CD}^{+}$and $\mathrm{CD} 19^{+}$ cells, but higher Kyn/Trp ratio than subjects with total ADL independence. 


\section{Discussion}

It is well known that several immune functions decline with increasing age. This phenomenon is known as immunosenescence and is partially responsible for the increased prevalence and severity of infectious diseases, enhanced autoimmunity, and low efficacy of vaccination in older adults (Mahbub et al., 2011; Pawelec, 2006). Immunosenescence is associated with changes in concentrations of several immune markers including those evaluated in this study. Lymphocyte subsets were reported to vary with increasing age, affecting particularly to $\mathrm{T}$ and $\mathrm{B}$ lymphocyte populations. Previous studies reported decreased number of $\mathrm{CD}^{+}, \mathrm{CD}^{+}, \mathrm{CD}^{+}$, and $\mathrm{CD} 19^{+}$cells (Miller, 1996; Weiskopf et al., 2009; Hirokawa et al., 2013). Accordingly, in our study, age-related reduction in \% $\mathrm{CD}^{+}$, $\mathrm{CD}^{+}, \mathrm{CD} 9^{+}$cells, and in $\mathrm{CD}^{+} / \mathrm{CD}^{+}$ratio was also observed. Together with changes in lymphocyte subsets, aging has been also associated with elevated levels of circulating inflammatory mediators. In particular, alterations in levels of several pro-inflammatory and anti-inflammatory cytokines, increased plasma neopterin and kynurenine levels, diminished tryptophan concentrations, and, consequently, higher Kyn/Trp ratio were noted in older subjects as compared to younger populations (Capuron et al., 2011; Theofylaktopoulou et al., 2013; Badawy, 2015). All these changes are consistent with a chronic low-grade inflammatory state in older adults that may lead to chronic illnesses such as cardiovascular diseases, type II diabetes mellitus, Alzheimer's disease, osteoporosis, and certain cancers (Simpson et al., 2012).

It is generally accepted that regular physical exercise is associated with increased longevity and lower risk of developing cardiovascular diseases, diabetes, metabolic syndrome, hypertension, infectious illnesses, and cancer (Simpson et al., 2012). However, the positive influence of physical activity on immune system in older subjects is still unclear, with studies reporting either positive or no marked effects on immune responses (Campbell et al., 2008; Kapasi et al., 2003; Woods et al., 2012). As the etiology of many age-related diseases has been attributed to a dysfunctional immune system, exploring the impact of physical activity on aging immunity may lead to important benefits for older adults, helping to reduce or delay immunosenescence development. Indeed, there has been interest in manipulation of certain lifestyle factors, including promoting physical activity, as a way of moderating the effects of aging on the immune system (Simpson et al., 2012).

Different immunological parameters were examined in this study including \% lymphocyte subpopulations and levels of serum neopterin and tryptophan metabolism products. Previously, physical activity was found to alter, among other parameters, $\% \mathrm{CD}^{+}$and $\mathrm{CD}^{+}$cells (Unal et al., 2005), and number of $\mathrm{CD}^{+}$cells (Hong et al., 2004) in young individuals aged $<40$ years old, and to lower the absolute counts of circulating NK cells in athletes (Rama et al., 2013), in healthy male volunteers exposed to a physical stress ( $1 \mathrm{~h}$ cycloergometer exercise) (Mignini et al., 2008), and in young subjects (mean age around 25 years old) after performing an 8 -week training program (Unal et al., 2005). Nevertheless, it seems that physical activity did not markedly affect lymphocyte subsets in older subjects after performing long-term exercise training, either in sedentary individuals (Nieman et al., 1993; Woods et al., 1999; Drela et al., 2004; Raso et al., 2007; Neves et al., 2009), or inactive subjects living in a nursing home (Kapasi et al., 2003) or reporting running or jogging (Shinkai et al., 1995). In the present study, higher $\mathrm{CD} 4^{+} / \mathrm{CD}^{+}$ratio and lower $\% \mathrm{CD} 19^{+}$cells were observed in individuals with reduced physical activity following univariate analysis; however, only the difference in $\mathrm{CD}^{+} / \mathrm{CD}^{+}$ratio was maintained following multivariate analysis, with a $45 \%$ rise compared to normal physical activity group.

Several investigators determined the influence of acute exercise on immune system and considered aging as a factor (Ceddia et al., 1999; Mazzeo et al., 1998; Bruunsgaard et al., 1999). In particular, some immunological markers were compared in two populations, one of the young individuals and another of older individuals, at rest and immediately after performing an acute bout of maximal exercise. Similar to our findings, data demonstrated increases in the $\mathrm{CD} 4^{+} / \mathrm{CD} 8^{+}$ratio in older subjects after exercise without significant alterations in other lymphocyte subsets. Previous studies in older adults reported elevation in number of T lymphocytes (Koizumi et al., 2003) and $\mathrm{CD}^{+}$cells (Shimizu et al., 2008; Koizumi et al., 2003) after performing the exercise training programs. However, in these cases, the number of individuals involved in each study was limited (27 and 28 individuals, respectively). Further, no marked changes in the distribution of lymphocyte subpopulations were observed in older women (62-86 years of age) after long-term (2 years) 
moderate physical activity compared to a sedentary control group, with also small sample size (30 vs. 12) (Drela et al., 2004). Therefore, some of the apparent inconsistencies regarding the influence of physical activity on lymphocyte subsets may be explained by (1) differences in experimental design, (2) training programs applied, (3) methods employed for physical activity evaluation, or (4) possible influence of other factors not considered in the analysis, such as clinical/epidemiological confounders or diurnal cycle (McFarlin et al., 2013). Terra et al. (2012) noted that moderate intensity exercise stimulated parameters related to cellular immunity and hence decreased the risk of infection, while high-intensity exercise may promote a decline of these same parameters, increasing the risk of infectious diseases. Although often used interchangeably in the literature, physical activity and exercise are quite different concepts and need to be considered in the interpretation and reliability of findings. As previously mentioned, physical activity refers to any activity performed during the daily life, while exercise is a specific form of physical activity planned with the intention of acquiring fitness or other health benefits (Carnethon et al., 2009).

Consequently, immune system modification is not necessarily the same in both cases. Moreover, in the case of training exercise, duration of the training program is also relevant, since it was previously found that lymphocyte subpopulations rise in the vascular compartment during exercise and diminish to levels lower than those found in pre-exercise period after long physical work duration (Hansen et al., 1991; Oshida et al., 1988). This may account for the negative results obtained in some cross-sectional and longitudinal exercise-training studies noting no marked effect of exercise on $\mathrm{CD}^{+} / \mathrm{CD}^{+}$ratio in older subjects (Woods et al., 1999; Campbell et al., 2008).

With respect to the analysis of neopterin and tryptophan metabolism products, results obtained from this study showed higher levels of serum neopterin and Kyn/Trp ratio and lower tryptophan concentrations in individuals with reduced physical activity. Tryptophan is an essential proteinogenic amino acid and neurotransmitter precursor. When immune stimulation occurs, $\mathrm{T}$ cells secrete interferon gamma (IFN $\gamma$ ), a potent stimulus for the enzyme indoleamine 2,3-dioxygenase (IDO) which catalyzes the transformation of tryptophan to form kynurenine. This phenomenon acts as a potent antimicrobial and antitumor mechanism and limits intracellular pathogen or tumor cell growth since it reduces the amount of tryptophan available for protein synthesis (Schröcksnadel et al., 2006). In vivo the ratio of kynurenine to tryptophan (Kyn/Trp) reflects tryptophan breakdown and represents an estimate of IDO activity (Widner et al., 1997). Neopterin is also involved in the inflammatory response, similar to tryptophan metabolism products, and its detection in body fluids is considered a sensitive marker of immune system activation (Murr et al., 2002). Neopterin is released from activated human monocytes/macrophages and therefore is an indicator of cell-mediated immunity (Murr et al., 2002). Significant correlations between tryptophan metabolism products and neopterin were reported by Schröcksnadel et al. (2006) and Widner et al. (2002) and are in agreement with our observations.

To the best of our knowledge, no apparent studies evaluating the influence of regular physical activity on these immunological parameters in older adults have been reported to date. Nevertheless, several investigations addressing immunological response after strong physical exercise in athletes demonstrated increases in neopterin levels, which usually return to basal values some hour after exercise (Castell et al., 1997; De Lucas et al., 2014; Strasser et al., 2016a; Tilz et al., 1993), and reduction in serum or plasma tryptophan concentrations (Baker et al., 2006; Ito et al., 1999; Strasser et al., 2016a). Similar results were described in rats, for which exercise was found to activate kynurenine pathway by elevating kynurenine levels and decreasing tryptophan concentrations (Ito et al., 2003). Indeed, kynurenine concentrations were also observed to be altered in rats after severe physical activity (Ito et al., 1999) or after acute exercise in individuals with normal glucose tolerance and with type II diabetes (Mudry et al., 2016). Increase in neopterin concentrations and fall in tryptophan levels were related to reduced physical activity in the current investigation in older adults, but strenuous exercise considered in the above-mentioned studies is different from physical activity measured in this study. Our results provide further support to previous studies showing that increasing physical activity may be effective for reducing chronic inflammation in older subjects (Woods et al., 2012). However, interpretation of current data might be contradictory as those subjects with an activated immune system (higher levels of neopterin) and lower tryptophan concentrations are less motivated to avoid a sedentary lifestyle and to perform physical activity. No marked alteration in serum kynurenine was found in our study which may be related to the specific aged 
population evaluated in this case, which was higher than 65 , compared to adult populations younger than 65 years old as measured in mentioned studies. It is of interest that Theofylaktopoulou et al. (2013) found that alterations in tryptophan metabolism products were reported to be associated with age. Considering reference ranges or basal levels previously described in older individuals for all tested immunological biomarkers, i.e., lymphocyte subsets (Valdiglesias et al., 2015), neopterin levels (Murr et al., 2002), and tryptophan metabolism products (Capuron et al., 2011), it is noteworthy that the number of individuals falling out of these ranges was higher in the reduced physical activity subjects, being particularly remarkable for the Kyn/Trp ratio with just $30 \%$ of values obtained falling within reference range.

There are several dissimilarities in the immunological response of males and females, likely because women are known to produce more robust humoral and cellular immune responses than men. However, the reason for the gender-related differences in immunosenescence is still a matter of discussion (Yan et al., 2010). Previous studies demonstrated differences between genders in \% immune cell subtypes (Jentsch-Ullrich et al., 2005; Yan et al., 2010). In our study, women showed significantly higher \% $\mathrm{B}\left(\mathrm{CD} 19^{+}\right)$and $\mathrm{T}\left(\mathrm{CD}^{+}\right)$lymphocytes, as well as significantly lower \% $\mathrm{NK}$ cells $\left(\mathrm{CD}_{16} 6^{+} 6^{+}\right)$. In agreement with these results, Abdullah et al. (2012) noted higher \% B lymphocytes in females $\left(\mathrm{CD} 19^{+}\right)$. Significantly higher concentrations of $\% \mathrm{CD}^{+}$and $\% \mathrm{CD} 4^{+}$cells, together with a lower \% NK cells, were also observed in women in Spanish (Andreu-Ballester et al., 2012; García-Dabrio et al., 2012) and Italian (Santagostino et al., 1999) populations. Further, Hirokawa et al. (2013) reported that age-related changes in different immunological parameters, including lymphocyte subsets and cytokine production, varied between men and women, as evidenced by a slower decline rate in these parameters in women. However, even though previous studies indicated that higher concentrations of tryptophan and kynurenine were detected in men (Laffon et al., 2013; 2016; Theofylaktopoulou et al., 2013), no significant gender-related differences were found in the present study, either for the serum neopterin levels or for tryptophan metabolism products.

The influence of smoking and alcohol and caffeine beverage consumption on immunological parameters was also examined, but none of these factors showed a significant effect on any of the biomarkers analyzed. Although some studies reported differences in immunological parameters between smokers and nonsmokers (Andreoli et al., 2014; Diamondstone et al., 1994; García-Dabrio et al., 2012; Jubri et al., 2013; Pedersen et al., 2011), alcohol liver disease patients and controls (Matos et al., 2013), and caffeine consumers and controls (Bishop et al., 2005), there are also a number of investigations demonstrating no marked influence of any of these factors on immune biomarkers (Touil et al., 2012; Fletcher \& Bishop, 2012; Valdiglesias et al., 2015).

In addition to exercise, immune function was previously reported to be influenced by other psychosocial (Kiecolt-Glaser et al., 2002) and nutritional (Meydani et al., 1997) factors. In this study, the possible effect of different clinical parameters including ADL dependence, deficient nutritional status, cognitive impairment, and depressive symptoms, on immunological biomarkers was also determined. Distribution of all selected clinical parameters considered was significantly different between subjects with normal and reduced physical activity. In particular, an elevated number of individuals with cognitive impairment, depressive symptoms, ADL dependence grade, and at risk or malnourished were observed in the reduced physical activity group. These findings were somewhat expected since a positive impact of physical exercise on cognitive impairment and depressive symptoms in older adults has been extensively identified in the literature (Klusmann et al., 2010; Bartholomew et al., 2005). Dependence and physical activity are highly related since a sedentary lifestyle was found to be a risk factor for muscle weakness that, subsequently, results in reduced activity levels, loss of muscle mass, and muscle strength (Landi et al., 2010). In addition, physical activity is related to dietary intake since the response of muscle cells to specific and different exercises is influenced by several nutritional factors (Rolland and Pillard, 2009).

Nutritional status and depressive symptoms were found not to markedly influence the immunological biomarkers. However, previous studies reported that nutritional deficiencies may weaken the immune system (Badawy, 2015), that alterations in some inflammatory parameters might be correlated with depressive episodes (Capuron et al., 2011), and that a diet rich in tryptophan and antioxidants may exert a positive impact on mood and cognition (Strasser et al., 2016b). 
Discrepancies with our results may be due to differences in age ranges of the populations analyzed or varying tools employed to assess nutritional status or depressive symptoms.

A significant influence was observed for cognitive status on $\% \mathrm{CD} 3^{+}, \% \mathrm{CD} 8^{+}$cells, both higher in individuals with cognitive impairment, and \% $\mathrm{CD} 16^{+} 56^{+}$lymphocytes lower in the same group. Alterations in the immune system and chronic inflammation play a prominent role in the pathogenesis of a number of neurological and neurobehavioral disorders involving cognitive impairment (Godbout \& Johnson, 2009; McAfoose \& Baune, 2009). Regarding lymphocyte subsets, even though some previous studies indicated no marked differences in levels of lymphocyte subpopulations related to cognitive status (Lombardi et al., 1999; Magaki et al., 2008; Bonotis et al., 2008), the proportions of both $\mathrm{CD}^{+}$(Lombardi et al., 1999) and $\mathrm{CD}^{+}$(Pirttila et al., 1992) lymphocytes were found to be decreased in Alzheimer's disease patients compared to healthy agedmatched controls. Moreover, alterations in number or functionality of NK cells $\left(\mathrm{CD} 16^{+} 56^{+}\right)$were previously noted in several age-related diseases including Alzheimer's and dementia (Camous et al., 2012), and increase in tryptophan degradation was reported in patients with Alzheimer's disease and mild cognitive impairment (Greilberger et al., 2010).

Influence of $\mathrm{ADL}$ dependence was also observed in $\% \mathrm{CD} 3^{+}$and $\% \mathrm{CD} 19^{+}$cells, lower in subjects with dependence, and in $\mathrm{Kyn} / \mathrm{Trp}$ ratio, higher in the same group. A majority of individuals with ADL dependence $(63 \%)$ lived in nursing homes, and nursing home residents are known to have numerous comorbidities, associated not only with physical inactivity but also with impaired immune response (Fahey et al., 2000). This might explain the noted influence of this condition on some immunological parameters in the present study. It also needs to be taken into account that older subjects with dependence spend most of their time indoors, at family home or elderly care centers, where the potential for exposure to indoor air contaminants is enhanced (Mendes et al., 2013). Thus, these subjects are commonly exposed to a higher level of pollutants that may also affect their immune system differently than subjects spending longer time outdoors.

In conclusion, results obtained in this study showed that several immune response biomarkers, in particular, certain lymphocyte subsets, serum levels of neopterin and tryptophan, and the Kyn/Trp ratio (indicative of IDO enzyme activity) were significantly different in study subjects with reduced physical activity compared to the group performing normal physical activity. Further, some of these immunological parameters were associated with cognitive impairment and functional status. These data contribute to reinforce the postulation that physical activity supports healthy aging, particularly by helping to protect the immunological system from aging-related changes.

\section{Acknowledgments}

Authors sincerely thank all the volunteers who participated in this study.

\section{Funding}

This work was supported by Xunta de Galicia (grant numbers ED431B 2016/013 and GPC2014/082) and IS1402 COST Action. V. Valdiglesias was supported by a Xunta de Galicia postdoctoral fellowship (reference ED481B 2016/190-0). M. Sánchez-Flores and D. Marcos-Pérez were supported by INDITEX-UDC fellowships. 


\section{References}

Abdullah, M., Chai, P. S., Chong, M. Y., Tohit, E. R., Ramasamy, R., Pei, C. P., and Vidyadaran, S. 2012. Gender effect on in vitro lymphocyte subset levels of healthy individuals. Cell Immunol. 272: 214-219.

Allison, D. J., and Ditor, D. S. 2014. The common inflammatory etiology of depression and cognitive impairment: A therapeutic target. J. Neuroinflammation. 11: 151.

Andreoli, C., Bassi, A., Gregg, E. O., Nunziata, A., Puntoni, R., and Corsini, E. 2014. Effects of cigarette smoking on circulating leukocytes and plasma cytokines in monozygotic twins. Clin. Chem. Lab. Med. 53: 57-64.

Andreu-Ballester, J. C., García-Ballesteros, C., Benet-Campos, C., Amigó, V., Almela-Quilis, A., Mayans, J., and Ballester, F. 2012. Values for ab and cd T-Lymphocytes and CD41, CD81, and CD561 subsets in healthy adult subjects: Assessment by age and gender. Cytomet. B Clin. Cytomet. 82: 238-244.

Badawy, A. A. 2015. Tryptophan availability for kynurenine pathway metabolism across the life span: Control mechanisms and focus on aging, exercise, diet and nutritional supplements. Neuropharmacology pii.: S0028-3908(15)30179-9.

Baker, J. S., Morgan, R., Hullin, D., Castell, L. M., Bailey, D. M., and Davies, B. 2006. Changes in blood markers of serotoninergic activity following high intensity cycle ergometer exercise. Res. Sports Med. 14: 191-203.

Bartholomew, J. B., Morrison, D., and Ciccolo, J. T. 2005. Effects of acute exercise on mood and well being in patients with major depressive disorder. Med. Sci. Sports Exercise 37: 20322037.

Baztán, J. J., Pérez del Molino, J., Alarcón, T., San Cristóbal, E., Izquierdo, G., Manzarbeitia, J. 1993. Índice de Barthel: Instrumento válido para la valoración funcional de pacientes con enfermedad cerebrovascular. Rev. Esp. Geriatr. Gerontol. 28: 32-40.

Bishop, N. C., Fitzgerald, C., Porter, P. J., Scanlon, G. A., and Smith, A. C. 2005. Effect of caffeine ingestion on lymphocyte counts and subset activation in vivo following strenuous cycling. Eur. J. Appl. Physiol. 93: 606-613.

Blesa, R., Pujol, M., Aguilar, M., Santacruz, P., Bertran-Serra, I., Hernández, G., Sol, J. M., PeñaCasanova, J., and NORMACODEM Group. 2001. NORMAlisation of cognitive and functional instruments for DEMentia: Clinical validity of the 'mini-mental state' for Spanish speaking communities. Neuropsychologia 39: 1150-1157.

Bonotis, K., Krikki, E., Holeva, V., Aggouridaki, C., Costa, V., and Baloyannis, S. 2008. Systemic immune aberrations in Alzheimer's disease patients. J. Neuroimmunol. 193: 183187.

Bruunsgaard, H., Jensen, M. S., Schjerling, P., Halkjaer-Kristensen, J., Ogawa, K., Skinhøj, P., and Pedersen, B. K. 1999. Exercise induces recruitment of lymphocytes with an activated phenotype and short telomeres in young and elderly humans. Life Sci. 35: 2623-2633.

Bruunsgaard, H., and Pedersen, B. K. 2000. Effects of exercise on the immune system in the elderly population. Immunol. Cell. Biol. 78: 523-531.

Camous, X., Pera, A., Solana, R., and Larbi, A. 2012. NK cells in healthy aging and ageassociated diseases. J. Biomed. Biotechnol. 2012: 195956.

Campbell, J.P., Guy, K., Cosgrove, C., Florida-James, G. D., and Simpson, R. J. 2008. Total lymphocyte CD8 expression is not a reliable marker of cytotoxic T-cell populations in human peripheral blood following an acute bout of high-intensity exercise. Brain Behav. Immun. 22: 375-380.

Capuron, L., Schroecksnadel, S., Féart, C., Aubert, A., Higueret, D., Barberger-Gateau, P., Layé, S., and Fuchs, D. 2011. Chronic low-grade inflammation in elderly persons is associated with altered tryptophan and tyrosine metabolism: Role in neuropsychiatric symptoms. Biol. Psychiat. 70: 175-182.

Carnethon, M., Whitsel, L. P., Franklin, B. A., American Heart Association Advocacy Coordinating Committee, Council on Epidemiology and Prevention, Council on the Kidney in Cardiovascular Disease, Council on Nutrition, Physical Activity and Metabolism et al. 2009. Worksite wellness programs for cardiovascular disease prevention: A policy statement from the American Heart Association. Circulation 120: 1725-1741.

Castell, L.M., Poortmans, J.R., Leclercq, R., Brasseur, M., Duchateau, J., and Newsholme, E. A. 1997. Some aspects of the acute phase response after a marathon race, and the effects of glutamine supplementation. Eur. J. Appl. Physiol. Occup. Physiol. 75: 47-53.

Ceddia, M. A., Price, E. A., Kohlmeier, C. K., Evans, J. K., Lu, Q., McAuley, E., and Woods, J. A. 1999. Differential leukocytosis and lymphocyte mitogenic response to acute maximal exercise in the young and old. Med. Sci. Sports Exercise 31: 829-836. 
Charlson, M. E., Pompei, P., Ales, K. L., and MacKenzie, C. R. 1987. A new method of classifying prognostic comorbidity in longitudinal studies: Development and validation. $J$. Chron. Dis. 40: 373-383.

de Labra, C., Guimaraes-Pinheiro, C., Maseda, A., Lorenzo, T., and Millán-Calenti, J. C. 2015. Effects of physical exercise interventions in frail older adults: A systematic review of randomized controlled trials. BMC Geriatr. 15: 154.

de Lucas, R. D., Caputo, F., Mendes de Souza, K., Sigwalt, A. R., Ghisoni, K., Lock Silveira, P. C., Remor, A. P., da Luz Scheffer, D., Guglielmo, L. G., and Latini, A. 2014. Increased platelet oxidative metabolism, blood oxidative stress and neopterin levels after ultraendurance exercise. J. Sports Sci. 32: 22-30.

Deleidi, M., Jäggle, M., and Rubino, G. 2015. Immune aging, dysmetabolism, and inflammation in neurological diseases. Front. Neurosci. 9: 172.

Diamondstone, L. S., Tollerud, D. J., Fuchs, D., Wachter, H., Brown, L. M., Maloney, E., Kurman, C. C., Nelson, D. L., and Blattner, W. A. 1994. Factors influencing serum neopterin and beta 2-microglobulin levels in a healthy diverse population. J. Clin. Immunol. 14: 368374.

Drela, N., Kozdron, E., and Szczypiorski, P. 2004. Moderate exercise may attenuate some aspects of immunosenescence. BMC Geriatr. 4: 8.

Fahey, J. L., Schnelle, J. F., Boscardin, J., Thomas, J. K., Gorre, M. E., Aziz, N., Sadeghi, H., and Nishanian, P. 2000. Distinct categories of immunologic changes in frail elderly. Mech. Ageing Dev. 115: 1-20.

Fletcher, D. K., and Bishop, N. C. 2012. Caffeine ingestion and antigen-stimulated human lymphocyte activation after prolonged cycling. Scand. J. Med. Sci. Sports. 22: 249-258.

Folstein, M. F., Folstein, S. E., and McHugh, P. R. 1975. 'Mini-Mental State'. A practical method for grading the cognitive state of patients for the clinician. J. Psychiat. Res. 12: 189-198.

Foster, R. K., and Marriott, H. E. 2006. Alcohol consumption in the new millennium - weighing up the risks and benefits for our health. Nutr. Bull. 31: 286-331.

Fried, L. P., Tangen, C. M., Walston, J., Newman, A. B., Hirsch, C., Gottdiener, J., Seeman, T., Tracy, R., Kop, W. J., Burke, G., and McBurnie, M. A. 2001. Frailty in older adults: Evidence for a phenotype. J. Gerontol. A Biol. Sci. Med. Sci. 56: M146-M156.

Fülöp, T., Dupuis, G., Witkowski, J. M., and Larbi, A. 2016. The role of immunosenescence in the development of age-related diseases. Rev. Invest. Clin. 68: 84-91.

Garber, C. E., Blissmer, B., Deschenes, M. R., Franklin, B. A., Lamonte, M. J., Lee, I. M., Nieman, D. C., Swain, D. P., and American College of Sports Medicine. 2011. American College of Sports Medicine position stand. Quantity and quality of exercise for developing and maintaining cardiorespiratory, musculoskeletal, and neuromotor fitness in apparently healthy adults: Guidance for prescribing exercise. Med. Sci. Sports Exercise 43: 1334-1359.

García-Dabrio, M. C., Pujol-Moix, N., Martinez-Perez, A., Fontcuberta, J., Souto, J. C., Soria, J. M., and Nomdedéu, J. F. 2012. Influence of age, gender and lifestyle in lymphocyte subsets: Report from the Spanish Gait-2 Study. Acta Haematol. 127: 244-249.

García-Lestón, J., Roma-Torres, J., Vilares, M., Pinto, R., Cunha, L. M., Prista, J., Teixeira, J. P., Mayan, O., Pásaro, E., Méndez, J., and Laffon, B. 2011. Biomonitoring of a population of Portuguese workers exposed to lead. Mutat Res. 721: 81-88.

Gnjidic, D., Hilmer, S. N., Blyth, S. M., Naganathan, V., Waite, L., Seibel, M. J., McLachlan, A J., Cumming, R. G., Handelsman, D. J., and Le Couteur, D. G. 2012. Polypharmacy cutoff and outcomes: Five or more medicines were used to identify community-dwelling older men at risk of different adverse outcomes. J. Clin. Epidemiol. 65: 989-995.

Godbout, J.P., and Johnson, R.W. 2009. Age and neuroinflammation: Alifetimeof psychoneuroimmune consequences. Immunol. Allergy Clin. North. Am. 29: 321-337.

Greilberger, J., Fuchs, D., Leblhuber, F., Greilberger, M., Wintersteiger, R., and Tafeit, E. 2010. Carbonyl proteins as a clinical marker in Alzheimer's disease and its relation to tryptophan degradation and immune activation. Clin. Lab. 56: 441-448.

Guigoz, Y., Vellas, B. J., and Garry, P. J. 1994. "Mini Nutritional Assessment (MNA): A practical assessment tool for grading the nutritional state of elderly patients". Facts and Research in Gerontology, edited by B. J. Y. Vellas, P. J. Guigoz, J. L. Garry, 15-60. Albarede, Serdi Publishing Co: New York.

Hansen, J. B., Wilsgard, L., and Osterud, B. 1991. Biphasic changes in leukocytes induced by strenuous exercise. Eur. J. Appl. Physiol. 62: 157-161.

Hirokawa, K. 1997. Reversing and restoring immune functions. Mech. Ageing Dev. 93: 119-124.

Hirokawa, K., Utsuyama, M., Hayashi, Y., Kitagawa, M., Makinodan, T., and Fulop, T. 2013. Slower immune system aging in women versus men in the Japanese population. Immun. Ageing 10: 19. 
Hong, S., Farag, N. H., Nelesen, R. A., Ziegler, M. G., and Mills, P. J. 2004. Effects of regular exercise on lymphocyte subsets and CD62L after psychological vs. physical stress. $J$. Psychosom. Res. 56: 363-370.

Ito, Y., Saito, K., Maruta, K., Nakagami, Y., Koike, T., Oguri, Y., and Nagamura, Y. 1999. Kynurenine concentration of serum was increased by exercise. Adv. Exp. Med. Biol. 467: 717-722.

Ito, Y., Yonekura, R., Maruta, K., Koike, T., Nakagami, Y., Shibata, K., Saito, K., and Nagamura, Y. 2003. Tryptophan metabolism was accelerated by exercise in rat. Adv. Exp. Med. Biol. 527: 531-535.

Jentsch-Ullrich, K., Koenigsmann, M., Mohren, M., and Franke, A. 2005. Lymphocyte subsets' reference ranges in an age- and gender-balanced population of 100 healthy adults-A monocentric German study. Clin. Immunol. 116: 192-197.

Jubri, Z., Latif, A. A., Top, A. G., and Ngah, W. Z. 2013. Perturbation of cellular immune functions in cigarette smokers and protection by palm oil vitamin E supplementation. Nutr. J. 12: 2 .

Kaiser, M. J., Bauer, J. M., Ramsch, C., Uter, W., Guigoz, Y., Cederholm, T., Thomas, D.R., Anthony, P., Charlton, K. E., Maggio, M., Tsai, A. C., Grathwohl, D., Vellas, B., Sieber, C. C., and MNA-International Group. 2009. Validation of the Mini Nutritional Assessment short-form (MNA-SF): A practical tool for identification of nutritional status. J. Nutr. Health Aging 13: 782-788.

Kapasi, Z. F., Ouslander, J. G., Schnelle, J. F., Kutner, M., and Fahey, J. L. 2003. Effects of an exercise intervention on immunologic parameters in frail elderly nursing home residents. $J$. Gerontol. A. Biol. Sci. Med. Sci. 58: 636-643.

Kiecolt-Glaser, J. K., McGuire, L., Robles, T. F., and Glaser, R. 2002. Psychoneuroimmunology: psychological influences on immune function and health. J. Consult. Clin. Psychol. 70: 537547.

Klusmann, V., Evers, A., Schwarzer, R. Schlattmann, P., Reischies, F. M., Heuser, I., and Dimeo, F. C. 2010. Complex mental and physical activity in older women and cognitive performance: A 6-month randomized controlled trial. J. Gerontol. A. 65: 680-688.

Koizumi, K., Kimura, F., Akimoto, T., Akama, T., Kumai, Y., Tanaka, H., Ishizu, M., Kuno, S., and Kono, I. 2003. Effects of long-term exercise training on peripheral lymphocyte subsets in elderly subjects. Jpn. J. Phys. Fitness Sports Med. 52: 193-202.

Laffon, B., Aguilera, F., Ríos-Vázquez, J., García-Lestón, J., Fuchs, D., Valdiglesias, V., and Pásaro, E. 2013. Endocrine and immunological parameters in individuals involved in Prestige spill cleanup tasks seven years after the exposure. Environ. Int. 59: 103-111.

Laffon, B., Pásaro, E., and Valdiglesias, V. 2016. Effects of exposure to oil spills on human health: Updated review. J Toxicol Environ Health B 19: 105-128.

Landi, F., Abbatecola, A. M., Provinciali, M., Corsonello, A., Bustacchini, S., Manigrasso, L., Cherubini, A., Bernabei, R., and Lattanzio, F. 2010. Moving against frailty: Does physical activity matter? Biogerontology. 11: 537-545.

Lombardi, V. R., Garcia, M., Rey, L., and Cacabelos, R. 1999. Characterization of cytokine production, screening of lymphocyte subset patterns and in vitro apoptosis in healthy and Alzheimer's Disease (AD) individuals. J. Neuroimmunol. 97: 163-171.

Magaki, S., Yellon, S. M., Mueller, C., and Kirsch, W. M. 2008. Immunophenotypes in the circulation of patients with mild cognitive impairment. J. Psychiat. Res. 42: 240-246.

Mahbub, S., Brubaker, A. L., and Kovacs, E. J. 2011. Aging of the innate immune system: An update. Curr. Immunol. Rev. 7: 104-115.

Mahoney, F. I., and Barthel, D. W. 1965. Functional evaluation: The Barthel index. Maryland State Med. J. 14: 61-65.

Martínez de la Iglesia, J., Onís Vilches, M. C., Dueñas Herrero, R., Albert Colomer, C., Aguado Taberné, C., and Luque Luque, R. 2002. The Spanish version of the Yesavage abbreviated questionnaire (GDS) to screen depressive dysfunctions in patients older than 65 years. MEDIFAM 12: 620-630.

Mathur, N., and Pedersen, B. K. 2008. Exercise as a mean to control low-grade systemic inflammation. Mediators Inflamm. 2008: 109502.

Matos, L. C., Batista, P., Monteiro, N., Ribeiro, J., Cipriano, M. A., Henriques, P., Girão, F., and Carvalho, A. 2013. Lymphocyte subsets in alcoholic liver disease. World J. Hepatol. 5: 4655.

Mazzeo, R. S., Rajkumar, C., Rolland, J., Blaher, B., Jennings, G., and Esler, M. 1998. Immune response to a single bout of exercise in young and elderly subjects. Mech. Ageing Dev. 100: $121-132$.

McAfoose, J., and Baune, B. T. 2009. Evidence for a cytokine model of cognitive function. Neurosci. Biobehav. Rev. 33: 355-366. 
McFarlin, B., Mitchell, J. B., McFarlin, M. A., and Steinhoff, G. M. 2013. Repeated endurance exercise affects leukocyte number but not NK cell activity. Med. Sci. Sports Exerc. 35: 11301138.

Mendes, A., Pereira, C., Mendes, D., Aguiar, L., Neves, P., Silva, S., Batterman, S., and Teixeira, J. P. 2013. Indoor air quality and thermal comfort-results of a pilot study in elderly care centers in Portugal. J. Toxicol. Environ. Health A 76: 333-344.

Meydani, S. N., Meydani, M., Blumberg, J. B., Leka, L. S., Sibe,r G., Loszewski, R., Thompson, C., Pedrosa, M. C., Diamond, R. D., and Stollar, B. D. 1997. Vitamin E supplementation and in vivo immune response in healthy elderly subjects. A randomized controlled trial. J. Am. Med. Assoc. 277: 1380-1386.

Mignini, F., Traini, E., Tomassoni, D., Vitali, M., and Streccioni, V. 2008. Leucocyte subset redistribution in a human model of physical stress. Clin. Exp. Hypertens. 30: 720-731.

Miller, R. A. 1996. The aging immune system: Primer and prospectus. Science 273: 70-74.

Mudry, J. M., Alm, P. S., Erhardt, S., Goiny, M., Fritz, T., Caidahl, K., Zierath, J. R., Krook, A., and Wallberg-Henriksson, H. 2016. Direct effects of exercise on kynurenine metabolism in people with normal glucose tolerance or type 2 diabetes. Diabetes Metab. Res. Rev. 32: 754 761

Murr, C., Widner, B., Wirleitner, B., and Fuchs, D. 2002. Neopterin as a marker for immune system activation. Curr. Drug Metab. 3: 175-187.

Nestlé Nutrition Institute. 2009. Guía para rellenar el formulario Mini Nutritional Assessment $\left(\mathrm{MNA}^{\circledR}\right)$. http://www.mna-elderly.com/mna_forms.html (accessed October 2016).

Neves, Sda C. Jr, Lima, R. M., Simões, H. G., Marques, M. C., Reis, V. M., and de Oliveira, R.J. 2009. Resistance exercise sessions do not provoke acute immunosuppression in older women. J. Strength Cond. Res. 23: 259-265.

Nieman, D. C., Henson, D. A., Gusewitch, G., Warren, B. J., Dotson, R. C., Butterworth, D. E., and Nehlsen-Cannarella, S. L. 1993. Physical activity and immune function in elderly women. Med. Sci. Sports Exercise 25: 823-831.

Oshida, Y., Yamanouchi, K., Hayamizu, S., and Sato, Y. 1988. Effect of acute physical exercise on lymphocyte subpopulations in trained and untrained subjects. Int. J. Sports Med. 9: 137140.

Pate, R. R., Pratt, M., Blair, S. N., Haskell, W. L., Macera, C. A., Bouchard, C., Buchner, D., Ettinger, W., Heath, G. W., King, A. C., Kriska, A., Leon, A. S., Marcus, B. H., Morris, J., Paffenbarger, R. S., Patrick, K., Pollock, M. L., Rippe, J. M., Sallis, J., and Wilmore, J. H. 1995. Physical activity and public health. A recommendation from the Centers for Disease Control and Prevention and the American College of Sports Medicine. J. Am. Med. Assoc. 273: 402-407.

Pawelec, G. 2006. Immunity and ageing in man. Exp. Gerontol. 41: 1239-1242.

Pedersen, E. R., Midttun, Ø., Ueland, P. M., Schartum-Hansen, H., Seifert, R., Igland, J., Nordrehaug, J. E., Ebbing, M., Svingen, G., Bleie, Ø., Berge, R., and Nygård, O. 2011. Systemic markers of interferon- $\gamma$-mediated immune activation and long-term prognosis in patients with stable coronary artery disease. Arterioscler. Thromb. Vasc. Biol. 31: 698-704.

Peterson, M. J., Giuliani, C., Morey, M. C., Pieper, C. F., Evenson, K. R., Mercer, V., Cohen, H. J., Visser, M., Brach, J. S., Kritchevsky, S. B., Goodpaster, B. H., Rubin, S., Satterfield, S., Newman, A. B., Simonsick, E. M., and Health, Aging and Body Composition Study Research Group. 2009. Physical activity as a preventative factor for frailty: The health, aging, and body composition study. J. Gerontol. A 64A: 61-68.

Pirttila, T., Mattinen, S., and Frey, H. 1992. The decrease of CD8-positive lymphocytes in Alzheimer's disease. J. Neurol. Sci. 107: 160-165.

Rama, L., Teixeira, A. M., Matos, A., Borges, G., Henriques, A., Gleeson, M., Pedreiro, S., Filaire, E., Alves, F., and Paiva, A. 2013. Changes in natural killer cell subpopulations over a winter training season in elite swimmers. Eur. J. Appl. Physiol. 113: 859-868.

Raso, V., Benard, G., Da Silva Duarte, A. J., and Natale, V. M. 2007. Effect of resistance training on immunological parameters of healthy elderly women. Med. Sci. Sports. Exercise. 39: 2152-2159.

Rolland, Y., Pillard, F. 2009. Validated treatments and therapeutic perspectives regarding physical activities. J. Nutr. Health Aging. 13: 742-745.

Ruiz Comellas, A., Pera, G., Baena Díez, J. M., Mundet Tudurí, X., Alzamora Sas, T., Elosua, R., Torán Monserrat, P., Heras, A., Forés Raurell, R., Fusté Gamisans, M., and Fàbrega Camprubí, M. 2012. Validation of a Spanish short version of the Minnesota leisure time physical activity questionnaire (VREM). Rev. Esp. Salud Publica. 86: 495-508.

Santagostino, A., Garbaccio, G., Pistorio, A., Bolis, V., Camisasca, G., Pagliaro, P., and Girotto, M. 1999. An Italian national multicenter study for the definition of reference ranges for normal values of peripheral blood lymphocyte subsets in healthy adults. Haematologica. 84: 499-504. 
Saunders, J. B., Aasland, O. G., Babor, T. F., De La Fuente, J. R., and Grant, M. 1993.

Development of the alcohol use disorders identification test (AUDIT): WHO collaborative project on early detection of persons with harmful alcohol consumption- II. Addiction 88: 791-804.

Schröcksnadel, K., Wirleitner, B., Winkler, C., and Fuchs, D. 2006. Monitoring tryptophan metabolism in chronic immune activation. Clin. Chim. Acta. 364: 82-90.

Sheikh, J. L., and Yesavage, J. A. 1986. Geriatric Depression Scale (GDS). Recent evidence and development of a shorter version. Clin. Gerontol. 5: 165-172.

Shimizu, K., Kimura, F., Akimoto, T., Akama, T., Tanabe, K., Nishijima, T., Kuno, S., and Kono, I. 2008. Effect of moderate exercise training on T-helper cell subpopulations in elderly people. Exercise. Immunol. Rev. 14: 24-37.

Shinkai, S., Kohno, H., Kimura, K., Komura, T., Asai, H., Inai, R., Oka, K., Kurokawa, Y., and Shephard, R. 1995. Physical activity and immune senescence in men. Med. Sci. Sports Exercise 27: 1516-1526.

Simpson, R. J., Lowder, T. W., Spielmann, G., Bigley, A. B., LaVoy, E. C., and Kunz, H. 2012. Exercise and the aging immune system. Ageing Res. Rev. 11: 404-420.

Strasser, B., Geiger, D., Schauer, M., Gatterer, H., Burtscher, M., and Fuchs, D. 2016a. Effects of exhaustive aerobic exercise on tryptophan-kynurenine metabolism in trained athletes. PLoS One 11: $\mathrm{e} 0153617$.

Strasser, B., Gostner, J.M., Fuchs, D. 2016b. Mood, food and cognition: Role of tryptophan and serotonin. Curr. Opin. Clin. Nutr. Metab. Care 19: 55-61.

Terra, R., Gonçalves da Silva, S. A., Salerno Pinto, V., and Lourenço Dutra, P. M. 2012. Effect of exercise on the immune system: Response, adaptation and cell signaling. Rev. Bras. Med. Esporte. 18: 208-14.

Theofylaktopoulou, D., Midttun, Ø., Ulvik, A., Ueland, P. M., Tell, G. S., Vollset, S. E., Nygård, O., and Eussen, S. J. 2013. A community-based study on determinants of circulating markers of cellular immune activation and kynurenines: The Hordaland Health Study. Clin. Exp. Immunol. 173: 121-130.

Tilz, G. P., Domej, W., Diez-Ruiz, A., Weiss, G., Brezinschek, R., Brezinschek, H. P., Hüttl, E., Pristautz, H., Wachter, H., and Fuchs, D. 1993. Increased immune activation during and after physical exercise. Immunobiology 188: 194-202.

Touil, N., Hadef, R., Lemnouer, A., Zrara, A., Sbai, A. I., Belfquih, B., Mrani, S., Benkirane, A. Ouaaline, M., and Mrabet, M. 2012. Range-reference determination of lymphocyte subsets in Moroccan blood donors. Afr. Health. Sci. 12: 334-338.

Unal, M., Erdem, S., and Deniz, G. 2005. The effects of chronic aerobic and anaerobic exercises n lymphocyte subgroups. Acta Physiol. Hung. 92: 163-171.

Valdiglesias, V., Sánchez-Flores, M., Maseda, A., Marcos-Pérez, D., Millán-Calenti, J. C., Pásaro, E., Lorenzo-López, L., and Laffon, B. 2015. Lymphocyte subsets in a population of nonfrail elderly individuals. J. Toxicol. Environ. Health A. 78: 790-804.

Weiskopf, D., Weinberger, B., and Grubeck-Loebenstein, B. 2009. The aging of the immune system. Transplant. Int. 22: 1041-1050.

Widner, B., Laich, A., Sperner-Unterweger, B., Ledochowski, M., and Fuchs, D. 2002. Neopterin production, tryptophan degradation, and mental depression-what is the link? Brain Behav. Immun. 16: 590-595.

Widner, B., Werner, E. R., Schennach, H., Wachter, H., and Fuchs, D. 1997. Simultaneous measurement of serum tryptophan and kynurenine by HPLC. Clin. Chem. 43: 2424-2426.

Woods, J. A., Ceddia, M. A., Wolters, B. W., Evan, J. K., Lu, Q., and McAuley, E. 1999. Effects of 6 months of moderate aerobic exercise training on immune function in the elderly. Mech. Ageing Dev. 109: 1-19.

Woods, J. A., Wilund, K. R., Martin, S. A., and Kistler, B. M. 2012. Exercise, inflammation and aging. Aging Dis. 3: 130-140.

Yan, J., Greer, J. M., Hull, R., O’Sullivan, J. D., Henderson, R. D., Read, S. J., and McCombe, P. A. 2010. The effect of ageing on human lymphocyte subsets: Comparison of males and females. Immun. Ageing. 7: 4. 